\title{
Sensitization to Common Allergens in Adults with Asthma
}

\author{
Felicia Allen-Ramey, PhD, William F. Schoenwetter, MD, Thomas W. Weiss, DrPH, \\ David Westerman, MD, Nasira Majid, MD, and Leona E. Markson, ScD
}

Purpose: To estimate the prevalence of atopy (ie, allergen sensitization) in a sample of adult asthma outpatients.

Methods: Population consisted of a total of 218 patients, 18 to 55 years of age, who were currently receiving care for asthma; and 13 physicians, whose specialties were Family Practice, Allergy, or Pulmonology and who were providing care to at least 10 to 15 asthma patients weekly. Patients provided a blood sample for quantification of total and allergen-specific IgE. Outcomes were the proportion of patients with atopy and the proportions of patients with elevated serum IgE specific to each of 8 specific common allergens.

Results: The patients' mean age was 42 years, and $74 \%$ were women; $68 \%$ of patients met the study definition of atopy. Total serum IgE $\geq 114 \mathrm{kU} / \mathrm{L}$ was observed in $48 \%$ of patients, and $59 \%$ had elevated levels of IgE specific to one or more of 8 common allergens.

Conclusions: The majority of adult asthma outpatients had evidence of atopy and most were sensitive to a specific identifiable allergen. Awareness of the high prevalence of atopy among asthma patients might improve patient management. (J Am Board Fam Pract 2005;18:434-9.)

Atopy, classically defined as a personal or familial predisposition to become sensitized and produce $\mathrm{IgE}$ antibodies in response to normal exposure to common environmental allergens, is the strongest identifiable predisposing factor for developing asthma. ${ }^{1,2}$ Atopy may be defined operationally in terms of elevated total $\mathrm{IgE}$ and/or sensitization to specific allergens, determined by serologic testing or skin prick tests. The average proportion of cases of adult asthma attributable to atopy in populationbased studies is approximately $30 \%$ to $40 \%$

Submitted, revised 21 April 2005.

From Outcomes Research and Management, Merck \& Co., Inc., West Point, PA (FAR, TWW, LEM); Brainerd Medical Center, Brainerd, MN (WFS); Atlanta Pulmonary Group, Atlanta, GA (DW); and Temple University Hospital, Philadelphia, PA (NM).

Funding: This study was funded by Merck \& Co., Inc.

Conflict of interest: FAR, TWW, and LEM are employees of Merck \& Co., Inc. WFS, DW, and NM received research funds from Merck \& Co., Inc. as study investigators.

Corresponding author: Thomas W. Weiss, DrPH, Merck \& Co., Inc., P.O. Box 4(WP39-170), West Point, PA 19486 (e-mail: Thomas_Weiss@merck.com).

A portion of the data contained in this manuscript was previously presented at the following meetings: American Thoracic Society 99th International Conference, Seattle, WA, May 2003; National Conference on Asthma, Washington, DC, June 2003; and American College of Chest Physicians Annual Meeting, Orlando, FL, October 2003. (roughly twice that for non-asthmatics), although estimates range up to $80 \%$ in some studies. ${ }^{3,4} \mathrm{Ev}$ idence suggests that sensitization to common allergens, including molds and dust mites, correlates with greater asthma severity. ${ }^{5-7}$

Knowledge of sensitivity to specific allergens is an important guide to asthma management, through allergen avoidance, immunotherapy, and pharmacological treatment of allergies. Updated National Asthma Education and Prevention Program (NAEPP) guidelines recommend allergy testing for persons with persistent asthma and, after sensitivity is determined, avoidance of the trigger and allergen abatement. ${ }^{8}$ Few studies done in the United States, however, have provided information about atopy and adult asthma ${ }^{5,6,9}$ or investigated the extent to which measurement of atopy might influence medical decisions. Because more than 4 million visits per year by asthma patients are to family practitioners and other generalists, ${ }^{10}$ awareness of the prevalence of atopy among asthma patients may help to improve asthma patient management by these physicians. The objectives of this study, therefore, were 2-fold: to estimate the prevalence of atopy in a sample of US-based adult asthma outpatients using serologic testing; and to 
investigate whether physicians found in vitro testing for atopy sufficiently informative for them to consider a change in asthma management.

\section{Methods}

\section{Study Design and Populations}

A broad-based invitation was sent to physicians who had previously expressed an interest in collaborating with Merck \& Co., Inc. on studies of respiratory disease. Physicians were invited to participate in the study if they were board certified, were providing care to 10 to 15 asthma patients per week, and willing to seek Institutional Review Board approval. Between May and August 2002, surveys of patients and physicians were conducted at 13 outpatient clinical practices located in all 4 geographic regions of the United States (northeast, 3; south, 3; midwest, 5; west, 2). Physicians were asked to consecutively recruit between 15 and 20 patients coming to each study clinic for a routine visit. Patients were included in the study if they had documented, physician-diagnosed asthma, were 18 to 55 years of age, had reviewed and signed an informed consent form, and allowed a blood sample to be drawn. Patients were excluded if they had received immunosuppressive therapy in the previous 3 months, were currently receiving immunotherapy, or had a documented diagnosis of a nonatopic syndrome resulting in elevated total serum $\mathrm{IgE}$ - these included immunodeficiency disease (HIV/AIDS), IgE myeloma, drug-induced interstitial nephritis, graft versus host disease, parasitic diseases, skin diseases (ie, non-atopic eczema, allergic contact dermatitis, toxic epidermal necrolysis), or hyper-IgE syndrome.

\section{Data Collection}

A patient questionnaire, completed at the time of enrollment, recorded demographic data, family histories of asthma and allergies, and whether the patient had ever been told by any doctor or medical provider that he or she had allergies to food, animals (such as cats, dogs), or household dust, or that he or she had hay fever. The patients' blood samples were sent for serologic testing to a central laboratory (Quest Diagnostics), which determined total serum $\operatorname{IgE}$ concentration and the presence of $\mathrm{IgE}$ specific to 8 allergens (rye grass, Bermuda grass, birch, cockroach, Dermatophagoides farinae, ragweed, cat dander, and Alternaria alternata) using
ImmunoCAP. In vitro testing was chosen for its performance characteristics, convenience, and because it may offer a more standardized approach than skin testing. ${ }^{11}$ Performance studies of ImmunoCAP have shown this test to yield $85 \%$ to $94 \%$ sensitivity, $93 \%$ to $100 \%$ specificity, and $90 \%$ positive predictive value. ${ }^{11,12}$ A physician survey, completed after receipt of the patients' laboratory results, queried whether each patient's serologic test results would prompt a change in patient management. Physicians were asked to check "yes" or "no" in response to 2 questions. (1) Did the in vitro testing provide any new information that may be used to guide this patient's medical management plan? (2) Would you consider making any changes in asthma management for this patient, on learning this patient's allergy test results? Respondents who checked yes for the second question were asked "If yes, what would you consider changing in this patient's asthma management?" The 4 choices were:

1. Add medications to control allergy symptoms

2. Add immunotherapy

3. Change or discontinue current anti-asthma medications

4. Discuss allergen avoidance and environmental modifications in the home and office

There were no protocol-driven processes to alter the usual treatment provided by physicians in the study.

\section{Data Analysis}

The main study outcomes were the proportion of patients with atopy and the proportions of patients with elevated serum $\operatorname{IgE}$ specific to each of 8 specific allergens. Atopy was defined in this study as an elevated total serum IgE and/or elevated IgE specific to one of the 8 allergens tested. A total serum $\mathrm{IgE}$ concentration of $\leq 114 \mathrm{kU} / \mathrm{L}$ was considered to be normal based on reference ranges provided by the central laboratory. Elevated serum concentrations of allergen-specific IgEs were determined by the central laboratory in reference to normal ranges for each allergen. Descriptive statistics were computed. The $\chi^{2}$ test of proportions was used to determine whether responses to the physician survey were significantly different by physician specialty. 


\section{Results}

\section{Patient Population}

A total of 218 adults with asthma were eligible for inclusion in the study and were tested for evidence of atopy. There was an average of 17 patients per study site (range 7 to 20). Their mean age was 42 years and $74 \%$ were women (Table 1). Most patients had a family history of asthma (57\%) or allergies (64\%).

\section{Atopy and Specific Allergen Sensitivities}

Serologic testing indicated that $48 \%$ of patients had elevated total serum $\operatorname{IgE}$ and $59 \%$ of all studied patients had elevated levels of $\operatorname{IgE}$ specific to one or more of 8 common allergens (Table 2). A total of $68 \%$ of patients met the study definition of atopy, whereas $21 \%$ had elevated $\operatorname{IgE}$ to one or more specific antigens but normal total IgE. Thirtyseven percent had both elevated total serum $\operatorname{IgE}$ and elevated levels of $\mathrm{IgE}$ specific to one or more of 8 common allergens. The most frequent specific allergen sensitivities were to cat dander, dust mite, and common ragweed (Table 2). Of 128 (59\%) patients who had elevated levels of one or more allergen-specific IgEs, $87 \%$ reported that they had ever been told by a doctor or medical provider that they either had allergies to animals such as cats or dogs $(70 \%)$, household dust $(73 \%)$, or food $(35 \%)$, or that they had hay fever (52\%). Overall atopic sensitivity ranged from $61 \%$ in the South to $77 \%$ in the Northeast (Table 2). The proportion of patients with atopy was similar across specialties, al-

\section{Table 1. Patient Characteristics}

\begin{tabular}{lc}
\hline & $\begin{array}{c}\text { Patients } \\
(\mathrm{N}=218)\end{array}$ \\
\hline Age, mean years & 42 \\
Women (\%) & 74 \\
Race/ethnicity (\%) & \\
White & 64 \\
African American & 19 \\
Hispanic & 9 \\
Asian & 2 \\
American Indian & 1 \\
N/A & 5 \\
Family history (\%) & \\
Asthma & 57 \\
Allergies & 64 \\
Region (\%) & \\
Northeast & 26 \\
South & 21 \\
Midwest & 40 \\
West & 14 \\
\hline
\end{tabular}

though the proportion with sensitivity to one or more allergens was lower for pulmonologists compared with family practitioners and allergists ( $\mathrm{Ta}-$ ble 3).

\section{Physician Survey}

Thirteen physicians participated in the study; their specialties were family practice $(\mathrm{N}=5)$, allergy $(\mathrm{N}=4)$, and pulmonology $(\mathrm{N}=4)$. As indicated in Table 4, 45\% of the serologic test results provided the physicians with new information that might be used to guide the patients' asthma management, and $40 \%$ of the results prompted consideration of a change in asthma management. Where a change in asthma management was considered, the change most often considered ( $70 \%$ of cases) was to discuss allergen avoidance with the patient. The serologic test information was more likely to be new and more likely to prompt consideration of a change in asthma management for patients of family practitioners than for patients of allergists or pulmonologists (Table 3). Among pulmonologists considering a change, they were more likely to add medication to control allergy symptoms or add immunotherapy than allergists or family practitioners. The type of change in patient pharmacological management considered was more likely to be addition of medication for patients of pulmonologists, but more likely to be a change or discontinuation of medications for patients of allergists.

\section{Discussion}

We investigated atopy in 218 adult asthmatics at 13 outpatient clinical practices throughout the United States using in vitro testing and patient and physician surveys. The prevalence of atopy, operationally defined as elevated total $\operatorname{IgE}$ and/or elevated allergen-specific IgE, was $68 \%$ and $59 \%$ with specific allergen sensitivities, most frequently to cat dander, dust mite, and common ragweed. The information from allergen-specific tests prompted physicians to consider a change in asthma management-most often to discuss allergen avoidance with the patient-in $40 \%$ of cases.

There are few published studies of atopy in adult asthmatics in the United States. The investigations that have been reported were at single sites and tended to have small sample sizes. ${ }^{5,6,9}$ In a study of patients being evaluated by radioallergosorbent 
Table 2. Distribution of Physician Sample and Atopy and Allergen Sensitivity by Region

\begin{tabular}{|c|c|c|c|c|c|}
\hline & Total & NE Region & South & Midwest & West \\
\hline Allergists (no.) & 4 & 1 & 0 & 3 & 0 \\
\hline Family physicians (no.) & 5 & 2 & 1 & 1 & 1 \\
\hline Pulmonologist (no.) & 4 & 0 & 2 & 1 & 1 \\
\hline Number of patients & 218 & 56 & 46 & 86 & 30 \\
\hline Overall atopic sensitivity (\%)* & 68 & 77 & 61 & 67 & 67 \\
\hline Elevated total $\operatorname{IgE}(\%)$ & 48 & 59 & 39 & 47 & 43 \\
\hline Sensitivity to $\geq 1$ specific allergen (\%) $\dagger$ & 59 & 68 & 48 & 57 & 63 \\
\hline Normal total $\operatorname{IgE}$ and $\geq 1$ specific allergen sensitivity (\%) & 21 & 44 & 39 & 36 & 41 \\
\hline \multicolumn{6}{|l|}{ Elevated IgE by allergen sensitivity (\%) } \\
\hline Cat dander & 32 & 43 & 24 & 27 & 40 \\
\hline Dust miteł & 28 & 25 & 30 & 31 & 20 \\
\hline Common ragweed & 27 & 43 & 22 & 21 & 20 \\
\hline Bermuda grass & 22 & 30 & 20 & 17 & 20 \\
\hline Mold $\S$ & 17 & 18 & 13 & 16 & 23 \\
\hline Birch & 17 & 25 & 13 & 12 & 20 \\
\hline Cockroach & 17 & 25 & 11 & 14 & 17 \\
\hline Rye grass & 11 & 12 & 9 & 11 & 17 \\
\hline
\end{tabular}

* Sensitivity to one or more specific allergens and/or total serum $\operatorname{IgE}>114 \mathrm{kU} / \mathrm{L}$, as determined by in vitro serological testing.

$\dagger$ Determined by in vitro serological testing.

$\neq$ Dermatophagoides farinae.

$\$$ Alternaria alternata.

testing in New York City, asthmatics were more likely than non-asthmatics to be hypersensitized to cat dander or dust mites (D. farinae) and to Deuteromycetes molds (Alternaria tenuis, Aspergillus fumigatus, and Cladosporium herbarum), whereas pollen (tree, grass, ragweed) hypersensitivity was not independently associated with asthma. ${ }^{9}$ Although cat dander was excluded from another New York City study of allergic sensitization, ${ }^{6}$ most $(83 \%)$ of the 29 adults with asthma had a positive skin prick test to at least one of 7 common allergens or allergen mixtures: ragweed, grasses, dust mite (Dermatophagoides pteronyssinus and D. farinae), and trees. ${ }^{6}$ At the Portland, OR, site in the European Community respiratory health survey (ECRHS) studies, $74 \%$ of the 39 participants with asthma were sensitized to at least one of 9 common aller- gens, the most frequent sensitizations being to timothy grass, $D$. pteronyssinus, birch, A. alternata, and cat. ${ }^{5}$ Thus, studies in the United States have consistently observed a high prevalence of atopy among adult asthmatics, with the distribution of specific allergen sensitivities varying between sites. The same observations were reported in the ECRHS studies conducted at 30 sites, mostly in Europe. ${ }^{5,13-16}$

Many studies have also explored the utility of total serum $\operatorname{IgE}$ as a marker of atopy and found some level of discordance with allergen-specific tests. ${ }^{3,17}$ In this study, $21 \%$ of patients had a positive allergen-specific test while exhibiting normal total $\mathrm{IgE}$. These results support the need to examine patient responses to particular allergens to aid in proper diagnosis and management. Further re-

Table 3. Percentage of Asthma Patients with Atopy and Allergen Sensitivity by Physician Specialty

\begin{tabular}{|c|c|c|c|c|}
\hline & $\begin{array}{c}\text { Overall } \\
\mathrm{N}=218(\%)\end{array}$ & $\begin{array}{c}\text { Family Practice } \\
\mathrm{N}=69(\%)\end{array}$ & $\begin{array}{c}\text { Allergist } \\
\mathrm{N}=75(\%)\end{array}$ & $\begin{array}{c}\text { Pulmonology } \\
\mathrm{N}=74(\%)\end{array}$ \\
\hline Overall atopic sensitivity* & 68 & 70 & 75 & 61 \\
\hline Elevated total IgE & 48 & 56 & 48 & 39 \\
\hline Sensitivity to $\geq 1$ specific allergen $\dagger$ & 59 & 61 & 68 & 47 \\
\hline Normal total $\operatorname{IgE}$ level and $\geq 1$ specific allergen sensitivity & 21 & 9 & 27 & 22 \\
\hline
\end{tabular}

* Sensitivity to one or more specific allergens and/or total serum IgE $>114 \mathrm{kU} / \mathrm{L}$, as determined by in vitro serological testing. $\dagger$ Determined by in vitro serological testing. $\chi^{2}$ test of proportions used to assess differences between groups: $P=.03$.

$\neq \chi^{2}: P=.02$ : 


\begin{tabular}{|c|c|c|c|c|c|}
\hline & $\begin{array}{c}\text { Overall } \\
(\mathrm{N}=218)\end{array}$ & $\begin{array}{l}\text { Family Practice } \\
\quad(\mathrm{N}=69)\end{array}$ & $\begin{array}{l}\text { Allergy } \\
(\mathrm{N}=75)\end{array}$ & $\begin{array}{l}\text { Pulmonology } \\
\quad(\mathrm{N}=74)\end{array}$ & $P$ Value \\
\hline Test results provided new information (\%) & 45 & 59 & 31 & 46 & $\leq .01$ \\
\hline $\begin{array}{l}\text { Would consider changes to asthma management } \\
\text { based on test results (\%) }\end{array}$ & 40 & 55 & 33 & 34 & $\leq .01$ \\
\hline $\begin{array}{l}\text { If yes, type of change considered (\%)* } \\
\text { Add medication to control allergy symptoms } \\
\text { Add immunotherapy } \\
\text { Change or discontinue asthma medications } \\
\text { Discuss allergen avoidance }\end{array}$ & $\begin{array}{l}38 \\
22 \\
45 \\
70\end{array}$ & $\begin{array}{l}21 \\
16 \\
39 \\
76\end{array}$ & $\begin{array}{l}44 \\
20 \\
68 \\
64\end{array}$ & $\begin{array}{l}56 \\
32 \\
32 \\
68\end{array}$ & $\begin{array}{c}\leq .01 \\
\text { NS† } \\
.02 \\
\text { NS }\end{array}$ \\
\hline
\end{tabular}

${ }^{*} \mathrm{~N}=88$ patients.

$\dagger$ NS, not significant at $P<.05$.

search should explore the relationship between total serum $\operatorname{IgE}$ and specific $\operatorname{IgE}$ in healthy patients.

The high prevalence of atopy among adult asthmatics should make physicians aware of the need to explore allergic symptoms with their asthma patients-both at the initial evaluation and periodically thereafter, since patients may acquire important new allergic sensitizations over time. In this study, a significant minority of patients identified as having specific allergies had never been told by a medical provider that they had allergies. Almost half of the serologic test results were informative for physicians, particularly family practitioners, and for two-fifths of patients prompted consideration of a change in patient management, most often to discuss allergen avoidance but also to adjust asthma medications and to add pharmacotherapy for allergies. This suggests that physicians, particularly the family practitioners, in this study did not always have sufficient information about patients' allergic status to guide their care. The serologic test results were less likely to provide new information to allergists than to family practitioners. However, the impact on change in therapy is beyond the scope of paper.

The interpretation of differences between specialties is limited by the small physician sample size and number of patients per physician. Thus, these results may not be representative of all practice types. The results are consistent with those of a previous study, which found that virtually all allergists discussed triggers and performed an allergy evaluation on their adult asthma patients, compared with only two-thirds to three-fourths of generalists. ${ }^{17}$ The greater attention paid by allergists to the allergic status of their asthma patients may contribute to the observed differences in asthma outcomes between generalists and allergists: patients of allergists were less likely than those of generalists to seek emergency medical care for their asthma and had greater improvement in asthma symptom scores. ${ }^{18}$

In conclusion, most adult asthma outpatients had evidence of atopy. Awareness of the high rate of atopy among asthma patients might improve patient management by prompting physicians to discuss allergen avoidance as well as medical treatment for both allergies and asthma.

We gratefully acknowledge Phong Duong, PharmD, for assistance with the conception and design of the study, the investigators that participated in this study, and the assistance of Alan Morrison, $\mathrm{PhD}$, in the preparation of this manuscript.

\section{References}

1. Johansson SG, Bieber T, Dahl R, et al. Revised nomenclature for allergy for global use: report of the Nomenclature Review Committee of the World Allergy Organization, October 2003. J Allergy Clin Immunol 2004;113:832-6.

2. Global strategy for asthma management and prevention. Updated from: NHLBI/WHO Workshop Report, 1995. Revised 2002. National Institutes of Health Publication No. 02-3659, 2002.

3. Pearce N, Pekkanen J, Beasley R. How much asthma is really attributable to atopy? Thorax 1999;54:26872.

4. Soriano JB, Anto JM, Sunyer J, et al. Risk of asthma in the general Spanish population attributable to specific immunoresponse. Spanish Group of the European Community Respiratory Health Survey. Int J Epidemiol 1999;28:728-34.

5. Zureik M, Neukirch C, Leynaert B, Liard R, Bousquet J, Neukirch F. Sensitisation to airborne moulds and severity of asthma: cross sectional study from European Community respiratory health survey. BMJ 2002;325:411-4. 
6. Akerman M, Valentine-Maher S, Rao M, et al. Allergen sensitivity and asthma severity at an inner city asthma center. J Asthma 2003;40:55-62.

7. Tunnicliffe WS, Fletcher TJ, Hammond K, et al. Sensitivity and exposure to indoor allergens in adults with differing asthma severity. Eur Respir J 1999;13: 654-9.

8. Williams SG, Schmidt DK, Redd SC, Storms W. Key clinical activities for quality asthma care. Recommendations of the National Asthma Education and Prevention Program. MMWR Recomm Rep 2003;52:1-8.

9. Lin RY, Williams KD. Hypersensitivity to molds in New York City in adults who have asthma. Allergy Asthma Proc 2003;24:13-8.

10. Stafford RS, Ma J, Finkelstein SN, Haver K, Cockburn I. National trends in asthma visits and asthma pharmacotherapy, 1978-2002. J Allergy Clin Immunol 2003;111:729-35.

11. Poon AW, Goodman CS, Rubin RJ. In vitro and skin testing for allergy: comparable clinical utility and costs. Am J Manag Care 1998;4:969-85.

12. Current issues relating to in vitro testing for allergen-specific IgE: a workshop report [editorial]. Ann Allergy Asthma Immunol 1999;82:407-12.

13. Burney P, Malmberg E, Chinn S, Jarvis D, Luczyn- ska C, Lai E. The distribution of total and specific serum $\operatorname{IgE}$ in the European Community Respiratory Health Survey. J Allergy Clin Immunol 1997;99: 314-22.

14. Janson C, Anto J, Burney P, et al. The European Community Respiratory Health Survey: what are the main results so far? European Community Respiratory Health Survey II. Eur Respir J 2001;18:598_ 611.

15. Plaschke P, Janson C, Norrman E, Bjornsson E, Ellbjar S, Jarvholm B. Association between atopic sensitization and asthma and bronchial hyperresponsiveness in Swedish adults: pets, and not mites, are the most important allergens. J Allergy Clin Immunol 1999; $104: 58-65$.

16. Boezen HM, Postma DS, Schouten JP, Kerstjens HA, Rijcken B. PEF variability, bronchial responsiveness and their relation to allergy markers in a random population (20-70 yr). Am J Respir Crit Care Med 1996;154:30-5.

17. Hamilton RG, Adkinson NF Jr. 23. Clinical laboratory assessment of IgE-dependent hypersensitivity. J Allergy Clin Immunol 2003;111(2 Suppl):S687-701.

18. Wu AW, Young Y, Skinner EA, et al. Quality of care and outcomes of adults with asthma treated by specialists and generalists in managed care. Arch Intern Med 2001;161:2554-60. 